\title{
Microsatellite multiplexes for the genetic analyses of northern pike (Esox lucius) populations
}

\author{
Magdalena Płecha, Hanna Panagiotopoulou, Danijela Popović, Aleksandra \\ Michalska-Parda, Robert Gromadka, Piotr Węgleński, Anna Stanković
}

Received - 29 October 2018/Accepted - 02 February 2019. Published online: 31 March 2019; OInland Fisheries Institute in Olsztyn, Poland Citation: Płecha M., Panagiotopoulou H., Popović D., Michalska-Parda A., Gromadka R., Węgleński P., Stanković A. 2019 - Microsatellite multiplexes for the genetic analyses of northern pike (Esox lucius) populations - Fish. Aquat. Life 27: 33-40.

\begin{abstract}
The northern pike (Esox lucius L.) is a commercially important fish that forms freshwater and brackish populations. While the first ecotype is still quite abundant, the second has suffered rapid declines in recent years. Populations inhabiting the Baltic coastal waters of Poland have been supported by stocking programs since the late
\end{abstract}

\footnotetext{
M. Płecha [ڤ"]

Department of Molecular Phylogenetics and Evolution, Institute of Botany, Faculty of Biology, Biological and Chemical Research Centre, University of Warsaw, Żwirki i Wigury 101, 02-089 Warsaw, Poland e-mail:
}

M. Płecha, H. Panagiotopoulou, D. Popović, A. Michalska-Parda, P. Węgleński, A. Stanković Institute of Genetics and Biotechnology, Faculty of Biology, University of Warsaw, Pawińskiego 5a, 02-106 Warsaw, Poland

\section{H. Panagiotopoulou, R. Gromadka, P. Węgleński, A. Stanković} Institute of Biochemistry and Biophysics, Polish Academy of Sciences Pawińskiego 5a, 02-106 Warsaw, Poland

\section{H. Panagiotopoulou}

Museum and Institute of Zoology, Polish Academy of Sciences,

Wilcza 64, 00-679 Warsaw, Poland

\section{Popović, P. Węgleński}

Laboratory of Paleogenetics and Conservation Genetics, Centre of New Technology, University of Warsaw

Banacha 2c, 02-097 Warsaw, Poland

\author{
A. Stanković \\ The Antiquity of Southeastern Europe Research Center, University of \\ Warsaw, 00-927 Warsaw, Poland
}

1990s. This study describes a multiplex microsatellite (msDNA) assay consisting of 12 loci divided conveniently into two amplification sets (Elu78, Elu87, B451, Elu37, B457, B16, B25, and Elu19, Elu76, B422, Elu2, Elu7). The assay was optimized for genetic analyses of freshwater and brackish populations. These multiplexes were successfully executed to obtain the genetic profiles of 668 individuals from 16 populations (Poland and Germany). The average number of alleles was equal to 10.4 , whereas the observed heterozygosity per locus ranged from 0.18 to 0.89 , with the average value of 0.64. The probability of the identity of the marker sets indicated the high power of identification of unique genotypes. Therefore, this molecular tool can be used to describe the genetic variability of populations, select the proper source of breeding material, and monitor the progress of stocking efforts in genetic conservation projects of this species.

Keywords: Conservation genetics, brackish and freshwater ecotypes, microsatellite loci (msDNA), multiplex PCR, northern pike (Esox lucius)

\section{Introduction}

The northern pike, Esox lucius L., is one of the most commercially important fish species, and it inhabits both freshwater and brackish ecosystems. Therefore, two such ecotypes can be distinguished among these 
fish (Laikre et al. 2005a, 2005b, Larsen et al. 2005, Larsson et al. 2015). Populations which have adapted to low salinity water conditions in Europe inhabit mainly coastal waters of the Baltic Sea and are considered more vulnerable than their freshwater counterparts (Wennerström et al. 2017). Over the last 30 years, constant declines in E. lucius coastal populations have been observed (Laikre et al. 2005a, 2005b, Mickiewicz and Wołos 2012, Larsson et al. 2015). This problem has not only been noted in Poland, but also in Denmark and Sweden. For example, in the Puck Bay (Poland) during the 1960s and 1970 s, this species was caught in quantities of 40-50 tons $\mathrm{a}^{-1}$, while during the 1990 s it was noted very rarely in catches (Kruk-Dowgiałło et al. 2008). Increasing water pollution and overexploitation can play key roles in population declines as has been noted in other threatened fish species such as sturgeon (Acipenser oxyrinchus Mitchill) (Moore et al. 2014) or salmon (Salmo salar L.) (Popović et al. 2014). Whenever a straightforward species restoration and maintenance plan is needed, genetic monitoring can be an optimal strategy, especially when designing long-term supporting breeding programs. Such programs have been implemented successfully with other fish species, i.e., delta smelt, Hypomesus transpacificus McAllister (Fisch et al. 2013) and anadromous steelhead, Oncorhynchus mykiss (Walbaum) (Araki et al. 2007).

Microsatellite loci (msDNA) are still one of the most popular markers applied in population and conservation genetics studies (Guichoux et al. 2011). They consist of one to six nucleotide motifs in tandem repeats. Microsatellites are characterized by elevated mutation rates that usually make them highly polymorphic (Guichoux et al. 2011). Because of their neutral variation, msDNA loci are useful in genetic fingerprinting and mapping, parentage and kinship identification, migration and demography (i.e., bottleneck identification), polymorphism, and in identifying the structure and effective size of population studies (Putman and Carbone 2014). Their application in multiplex PCR makes them not only a feasible and much less time-consuming but also a relatively inexpensive molecular tool, contradictorily to the amplification of one product in a single reaction or high throughput sequencing (Guichoux et al. 2011). They are rationally inexpensive in comparison to other molecular markers (Ekblom and Galindo 2011) that can be analyzed either using chromatograms like in the case of msDNA loci (i.e. SNPs) or by applying NGS sequencing. What is more, such large data sets are bioinformatically laborious and complicated to handle. Therefore, in some studies, like genetic monitoring programs that support the management of stocking and introductions, which usually require the analysis of hundreds or thousands of individuals, applying a relatively small marker set is sufficient to obtain satisfactory results and permits such projects to be economically affordable. To date, many microsatellites have been developed for non-model organisms, which is one of the most important arguments for utilizing these markers-it makes them a universal and convenient molecular technique for population genetics projects (Guichoux et al. 2011).

Thus, unsurprisingly, the first utilization of this method was recently presented by Ouellet-Cauchon et al. (2014) for a landscape genetics study of $E$. lucius populations from Lake Ontario and the St. Lawrence River in Canada. In this study four separate multiplex reactions for the amplification of 22 msDNA loci were constructed. Three years later, an application of the next four different multiplex sets was proposed by Gandolfi et al. (2017) in which 17 msDNA loci were amplified for genetic introgression studies of both E. lucius and Esox flaviae (southern pike) in Italy. In more geographically diverse populations (including possible observations of genetic differences between brackish and freshwater populations), some microsatellite markers, which were formerly considered to be polymorphic and unbiased, might unexpectedly become monomorphic or burdened with null alleles (Larsen et al. 2005, Putman and Carbone 2014). Consequently, the application of various multiplex microsatellite assays provides a wider spectrum of tools that can easily be chosen. In particular, this is important for E. lucius population genetic studies since this species has yet 

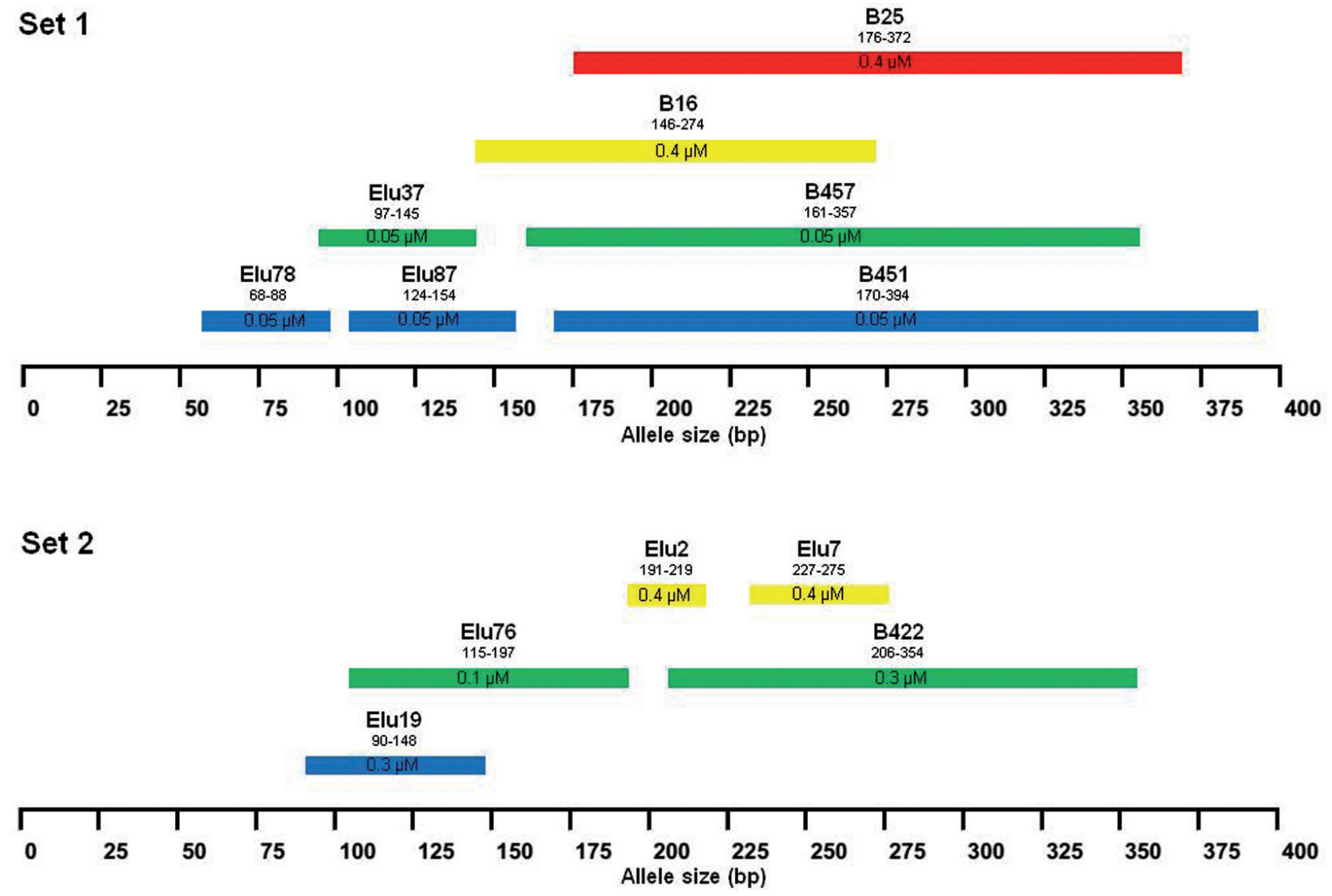

Figure 1. The msDNA multiplex assay acquired for the Esox lucius, divided into two amplification sets (Set 1 and Set 2). The obtained allele size ranges (positioned above the colored bars; (bp)) and optimized primer concentrations (marked inside the bars; $(\mu \mathrm{M})$ ) are given for each of the amplified loci. Bars are colored according to the fluorescent dyes (6-FAM (blue), HEX (green), TAMRA (yellow), or ROX (red), respectively) that were applied for the forward primer labelling.

to be studied in depth, and this information may prove to be useful.

This paper presents a solicitously arranged and optimized multiplex PCR assay that can be applied in fine-scale genetic analyses of either brackish or freshwater E. lucius populations. This method was developed for genetic population analyses that were included in a species restoration project in Poland. The assay is based on 12 highly polymorphic microsatellite markers arranged in two sets for loading on two sequencing panels.

\section{Materials and methods}

E. lucius samples were collected at 16 brackish and freshwater locations in Poland and Germany
(Supplement 1; permission for material collection was obtained from the local authorities). Fresh samples consisted of fragments of dorsal fins preserved in $96 \%$ ethanol and stored at $4^{\circ} \mathrm{C}$. DNA from samples $(\mathrm{N}=668)$ was extracted using the Wizard DNA (Promega) and DNA Mi-blood (Metabion) kits according to the manufacturers' protocols. The DNA was suspended or eluted with sterile double-distilled water to a final volume of $100 \mu \mathrm{l}$ and stored at $-20^{\circ} \mathrm{C}$. The DNA quality was tested with $1 \%$ agarose gel electrophoresis in $1 \times$ TBE buffer, whereas the average concentration was estimated using a spectrophotometer (NanoDrop ND - 1000 Technologies $\left.{ }^{\circledR}\right)$.

Before 2014, 51 E. lucius microsatellite loci had been described in the literature (Miller and Kapuscinski 1996, 1997, Hansen et al. 1999, 
Senanan and Kapuscinski 2000, Launey et al. 2003, Aguilar et al. 2005, Jacobsen et al. 2005, Wang et al. 2011). For the multiplex optimization, $16 \mathrm{msDNA}$ markers were selected primarily from those previously published. The selection criteria were as follows: high polymorphism, simple repeats, and published allele length according to which the markers could be assigned to two PCR reactions. There was also a greater inclination to accept loci that were optimized for populations located in latitudes similar to the populations under study. Using FastPCR v.3.8.41 software (Kalendar et al. 2009), the compatibility of the chosen primer pairs was confirmed in silico. Furthermore, potential primer-dimer formations were tested using default parameters. The PCR reactions for microsatellite amplification were performed with forward primers labelled with one of the following fluorescent dyes: 6-FAM, HEX, TAMRA, or ROX (Figure 1). First, the amplification of selected loci was tested using two different samples. Some of the markers (planned for: Set 1 - B259; Set 2 - B24, Elu64, B289) gave very weak products in the PCR reactions, and, thus, they were rejected from the assay. Considering all these aspects, 12 msDNAs were finally included (Table 1). The optimized reaction mixture $(10 \mu \mathrm{l})$ contained approximately 10-50 ng DNA, $1 \mathrm{x}$ MasterMix (Qiagen Multiplex Kit), and primers at the concentrations shown in Figure 1.

The reactions consisted of an initial denaturation step at $95^{\circ} \mathrm{C}$ for $15 \mathrm{~min}$, followed by 35 cycles of $30 \mathrm{~s}$ at $94^{\circ} \mathrm{C}$, annealing for $90 \mathrm{~s}$ at $61.5^{\circ} \mathrm{C}$ (Multiplex 1) or $63^{\circ} \mathrm{C}$ (Multiplex 2), and extension of $30 \mathrm{~s}$ at $70^{\circ} \mathrm{C}$, with the final extension step of $30 \mathrm{~min}$ at $60^{\circ} \mathrm{C}$. The PCR products were electrophoresed commercially (Oligo.pl, IBB, Warsaw, Poland) on an ABI3730/xl genetic analyzer (Applied Biosystems). Allele sizes were scored against the GeneScan LIZ 600 size standard (Applied Biosystems) using PeakScanner v.1.0 (Applied Biosystems).

Potential genotyping errors that might have been the result of stuttering and allelic dropouts were checked with MICRO-CHECKER v 2.2.3 freeware (Van Oosterhout et al. 2004) for each of the studied populations using 1,000 iterations and a 95\% confidence interval $(\mathrm{CI})$. The frequency of null alleles $\left(\mathrm{A}_{\mathrm{N}}\right)$ was estimated using 1,000 randomizations and a 95\% CI using Genepop v. 4.2 (Raymond and Rousset 1995) according to the Brookfield 1 method (Brookfield 1996) and FreeNa software (Chapuis and Estoup 2007), which implements the expectation-maximization (EM) algorithm (Dempster et al. 1977) with a bootstrap resampling over loci (number of replicates) fixed to 25,000. We used Arlequin v. 3.5.1.2 (Excoffier and Lischer 2010) to test for linkage disequilibrium (LD) using 1,000,000 permutations. The polymorphic information content (PIC) of the studied loci was calculated using Cervus v. 3.0 (Kalinowski et al. 2007), and the average polymorphism $(\mathrm{P})$ across all the markers used was calculated with GenAlEx v.6.5 (Peakall and Smouse 2006). The inbreeding coefficient ( $\mathrm{F}_{\mathrm{IS}}$ ) per locus was calculated using Genepop v. 4.2. Probabilities of identity (PI and PIsibs), the number of alleles $\left(\mathrm{N}_{\mathrm{A}}\right)$, and the expected $\left(\mathrm{H}_{\mathrm{E}}\right)$ and observed $\left(\mathrm{H}_{\mathrm{O}}\right)$ heterozygosities were calculated using GenAlEx v.6.5.

\section{Results and Discussion}

The two multiplexes developed were used to obtain microsatellite profiles of 668 individuals belonging to the 16 E. lucius populations located in Poland and Germany (Supplementary 1). The amplification effectiveness expressed by the total percentage of amplifications per locus was high and on the average equal to $98.45 \%$ (Table 1). Manual evaluation of the chromatograms proved them to be of good quality (lack of background noise and non-specific picks; Supplementary 2). Despite the large sample size, no loci product size overlapping was detected. The observed allele sizes of the studied loci showed some deviation when compared to data in the literature. An examination of allele frequencies indicated the existence of a few dominating alleles across the Elu-markers and a more normalized distribution with the B-markers (Supplementary 3). An automated examination of genotypes also failed to provide any evidence of scoring errors or large allele dropouts, although for some of the analyzed loci, the 


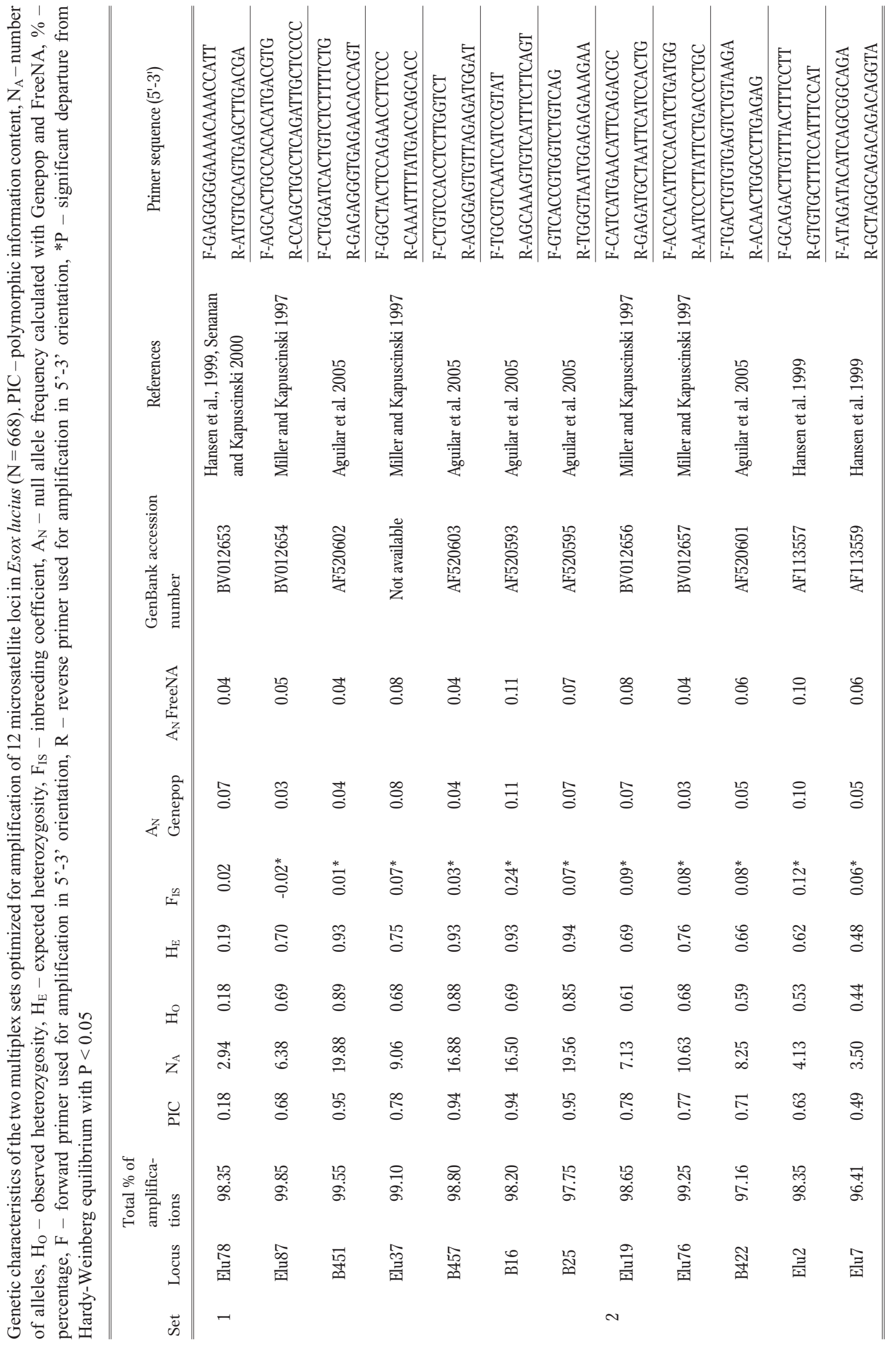


presence of null alleles was observed, especially for B16 and Elu2 (Table 1). However, only for locus B16 was this burden repetitive across almost all the studied populations, which was in contrast to Elu2, for which only a few populations exhibited this bias. These estimates for both markers were above the level assumed to be intermediate $\left(\mathrm{A}_{\mathrm{N}}>0.19\right)$ (Chapuis and Estoup 2007). Since the issue of null alleles has not been reported before for these markers (Larsen et al. 2005, Pedreschi et al. 2013), we believe that this is probably a characteristic of the studied populations rather than the loci per se.

The test for linkage disequilibrium showed that the microsatellite markers studied are not linked with each other. Furthermore, none of the loci pairs were repeatedly linked significantly across the 16 populations examined. The values of the probability of the identity of the markers set were $5 \times 10^{-17}$ (PI) and $1 \times 10^{-5}$ (PIsibs), which indicated the high power of identifying unique genotypes. The average PIC value of all the loci studied was $73 \%$ ( $\pm 22 \% \mathrm{SE}$ ); however, the $\mathrm{P}$ value calculated as a percentage of polymorphic loci across loci and populations was higher at $98.44 \%( \pm 0.84 \% \mathrm{SE})$. The average $\mathrm{N}_{\mathrm{A}}$ value was 10.4 (Table 1 ). The observed heterozygosity per locus ranged from $0.18( \pm 0.03$ $\mathrm{SE})$ to $0.89( \pm 0.02 \mathrm{SE})$ at an average value of 0.64 . These results are similar to those obtained when other European and Canadian E. lucius populations were tested using the same msDNA loci as in this study (Miller and Kapuscinski 1997, Hensen et al. 1999, Senanan and Kapuscinski 2000, Aguilar et al. 2004, Jacobsen et al. 2005, Laikre et al. 2005a, Larsen et al. 2005, Bosworth and Farrell 2006, Ouellet-Cauchon et al. 2014, Gandolfi et al. 2017). In the present study, for all individuals treated as a single population, the average $\mathrm{N}_{\mathrm{A}}$ value was 24.3 $( \pm 4.05 \mathrm{SE})$, with $\mathrm{H}_{\mathrm{O}}=0.65( \pm 0.05 \mathrm{SE})$. Therefore, the results indicated the usefulness of the established msDNA assay for genetically characterizing populations (i.e., genetic structure, isolation by distance, or effective population size estimations). The results of genetic polymorphism and structure of the populations described will be discussed in a separate work.
Multiplexing msDNA markers requires using challenging strategies (optimizing primer concentrations and annealing temperatures while considering clearly separated loci ranges and avoiding artefact amplification), notably when maximizing the number of polymorphic loci in a single PCR reaction (Guichoux et al. 2011). Thus, in summary, the multiplex assay presented will prove to be both a cost and time efficient molecular tool in population genetics studies and in conservation projects for E. lucius populations. It should prove very useful in describing the genetic diversity and structure of brackish and freshwater populations with the aim of supplying optimal solutions in the selection of populations that are genetically the closest for the stocking and reintroduction of E. lucius populations in the Baltic and North sea basins. In cases when data for more than 12 loci are required, i.e., relatedness assessments, it is recommend to combine the previously published multiplex assays (Ouellet-Cauchon et al. 2014, Gandolfi et al. 2017) in the analysis. The multiplex assay presented in this paper combines most of the msDNA markers utilized in the most recent studies of $E$. lucius populations (Ouellet-Cauchon et al. 2014, Bekkevold et al. 2015, Larsson et al. 2015, Gandolfi et al. 2017), so, as suggested by Wennerström et al. (2017), it is a convenient tool for comparative analyses.

Acknowledgments. We would like to thank J. Gawor for his support in obtaining raw msDNA data. We are thankful to Prof. T. Heese, Prof. W. Wawrzyniak, J. Konkel and T. Herman, M. and B. Raczkowski, M. and S. Kleszcz, R. Jachimowicz, Dr. E. Eschbach, Members of the Sea Fisheries Institute (Poland) and PZW 65 in Małkinia (Poland) for their help with sample collection. This work was supported by the project "ZOSTERA: Restoration of ecosystem key elements in the inner Puck Bay"; Polish National Centre for Research and Development through grant ZPB/62/72380/IT2/10; and CePT infrastructure financed by the European Union.

Authors contributions. M.P. designed and performed the experiments and analyzed the data. A.M-P. designed portions of the experiments. M.P., H.P., and D.P. wrote the manuscript. M.P. and R.G. assisted in 
material collection and raw data analysis. P.W. and A.S. directed the project.

\section{References}

Aguilar A., Banks J.D., Levine K.F., Wayne R.K. 2005 - Population genetics of northern pike (Esox lucius) introduced into Lake Davis, California - Can. J. Fish Aquat. Sci. 62: 1589-1599.

Araki H., Ardren W.R., Olsen E., Cooper B., Blouin M.S. 2007 - Reproductive success of captive-bred steelhead trout in the wild: Evaluation of three hatchery programs in the Hood River - Conserv. Biol. 21: 181-190.

Avise J.C. 2010 - Perspective: conservation genetics enters the genomics era - Conserv Genet 11: 665-669.

Bekkevold D., Jacobsen L., Hemmer-Hansen J., Berg S., Skov C. 2015 - From regionally predictable to locally complex population structure in a freshwater top predator: river systems are not always the unit of connectivity in Northern Pike Esox lucius - Ecol. Freshw. Fish. 24: 305-316.

Bosworth A., Farrell J. M. 2006 - Genetic divergence among Northern Pike from spawning locations in the upper St. Lawrence river - North Am. J. Fish. Manage. 26: 356-359.

Brookfield J.F.Y. 1996 - A simple new method for estimating null allele frequency from heterozygote deficiency - Mol. Ecol. 5: 453-455.

Chapuis M-P., Estoup A. 2007 - Microsatellite null alleles and estimation of population differentiation - Mol. Biol. Evol. 24: 621-631.

Dempster A., Laird N., Rubin D. 1977 - Maximum likelihood from incomplete data via the EM algorithm - J. R. Stat. Soc. Ser. B-Stat. 39: 1-38.

Ekblom R., Galindo J. 2011 - Applications of next generation sequencing in molecular ecology of non-model organisms - Heredity 107: 1-15.

Excoffier L., Lischer H.E.L. 2010 - Arlequin suite ver 3.5: a new series of programs to perform population genetics analyses under Linux and Windows - Mol. Ecol. Resour. 10: 564-567.

Fisch K.M., Ivy J.A., Burton R.S., May B. 2013 - Evaluating the performance of captive breeding techniques for conservation hatcheries: $\underline{A}$ case study of the delta smelt captive breeding program - J. Hered. 104: 92-104.

Gandolfi A., Ferrari C., Crestanello B., Girardi M., Lucentini L., Meraner A. 2017 - Population genetics of pike, genus Esox (Actinopterygii, Esocidae), in Northern Italy: evidence for mosaic distribution of native, exotic and introgressed populations - Hydrobiologia 794: 73-92.

Guichoux E., Lagache L., Wagner S., Chaumeil P., Leger P., Lepais O., Lepoittevin C., Malausa T., Revardel E., Salin
F., Petit R.J. 2011 - Current trends in microsatellite genotyping - Mol. Ecol. Resour. 11: 591-611.

Hansen M.M., Taggart J.B., Meldrup D. 1999 - Development of new VNTR markers for pike and assessment of variability at di- and tetranucleotide repeat microsatellite loci - J. Fish Biol. 55: 83-188.

Jacobsen B.H., Hansen M.M., Loeschcke V. 2005 Microsatellite DNA analysis of northern pike (Esox lucius L.) populations: insights into the genetic structure and demographic history of a genetically depauperate species - Biol. J. Linn. Soc. 84: 91-101.

Kalendar R., Lee, D. Schulman A.H. 2009 - FastPCR software for PCR primer and probe design and repeat search Gene Genomes and Genomics 3: 1-14.

Kalinowski S.T., Taper M.L., Marshall T.C. 2007 - Revising how the computer program CERVUS accommodates genotyping error increases success in paternity assignment - Mol. Ecol. 16: 1099-1106.

Kruk-Dowgiałło L., Szaniawska A. 2008 - Gulf of Gdansk and Puck Bay - In: Ecology of Baltic coastal waters. Ecological Studies 197 (Ed.) U. Schiewer, Springer, Verlag Berlin, Heidelberg: 139-165.

Laikre L., Miller L.M., Palme A., Palm S., Kapuscinski A.R., Thoresson G., Ryman N. 2005a - Spatial genetic structure of northern pike (Esox lucius) in the Baltic Sea - Mol. Ecol. 14: 1955-1964.

Laikre L., Palm S., Ryman N. 2005b - Genetic population structure of fishes: implications for coastal zone management - Ambio 34: 111-119.

Larsen P.F., Hansen M.M., Nielsen E.E., Jensen L.F., Loeschcke V. 2005 - Stocking impact and temporal stability of genetic composition in a brackish northern pike population (Esox lucius L.), assessed using microsatellite DNA analysis of historical and contemporary samples Heredity 95: 136-143.

Larsson P., Tibblin P., Koch-Schmidt P., Engstedt O., Nilsson J., Nordahl O., Forsman A. 2015 - Ecology, evolution, and management strategies of northern pike populations in the Baltic Sea - Ambio 44 (Suppl 3): 451-461.

Launey S., Krieg F., Morin J., Laroche J. 2003 - Five new microsatellite markers for northern pike (Esox lucius) Mol. Ecol. Notes 3: 366-368.

McMahon B.J., Teeling E.C., Höglund J. 2014 - How and why should we implement genomics into conservation? Evol. Appl. 7: 999-1007.

Mickiewicz M., Wołos A. 2012 - Economic ranking of the importance of fish species to lake fisheries stocking management in Poland - Arch. Pol. Fish. 20: 11-18.

Miller L.M., Kapuscinski A.R. 1996 - Notes: Microsatellite DNA markers reveal new levels of genetic variation in northern pike - Trans. Am. Fish. Soc. 125: 971-977.

Miller L.M., Kapuscinski A.R. 1997 - Historical analysis of genetic variation reveals low effective population size in 
a northern pike (Esox lucius) - Pop. Genetics 147: 1249-1258.

Moore J.S., Bourret V., Dionne M., Bradbury I., O’Reilly P., Kent M., Chaput G., Bernatchez L. 2014 - Conservation genomics of anadromous Atlantic salmon across its North American range: outlier loci identify the same patterns of population structure as neutral loci - Mol. Evol. 23: 5680-5697.

Ouellet-Cauchon G., Mingelbier M., Lecomte F., Bernatchez L. 2014 - Landscape variability explains spatial pattern of population structure of northern pike (Esox lucius) in a large fluvial system - Ecol. Evol. 4: 3723-3735.

Panagiotopoulou H., Popović D., Zalewska K., Węgleński P., Stanković A. 2014 - Microsatellite multiplex assay for the analysis of Atlantic sturgeon populations - J. Appl. Genet. 55: 505-510.

Peakall R., Smouse P.E. 2006 - GENALEX 6: Genetic analysis in Excel. Population genetic software for teaching and research - Mol. Ecol. Notes 6: 288-295.

Pedreschi D., Kelly-Quinn M., Caffrey J., O’Grady M., Mariani S. 2014 - Genetic structure of pike (Esox lucius) reveals a complex and previously unrecognized colonization history of Ireland - J. Biogeogr. 41: 548-560.

\section{Supporting information}

Additional supporting information may be found in the online version of this article.

Supplementary 1. Locations and sample sizes (N) of the studied Esox lucius populations (A) along with the map of locations (B).

Supplementary 2. Chromatograms of the msDNA loci (Set 1 and Set 2) for genetic analyses of the Esox lucius. Color picks - FAM (blue), HEX (green), TAMRA (black) or ROX (red) - correspond to the msDNA loci PCR products (single pick indicating
Popović D., Panagiotopoulou H., Baca M., Stefaniak K., Mackiewicz P., Makowiecki D., King T.L., Gruchota J., Węgleński P., Stanković A. 2014 - The history of sturgeon in the Baltic Sea - J. Biogeogr. 41: 1590-1602.

Putman A.I., Carbone I. 2014 - Challenges in analysis and interpretation of microsatellite data for population genetic studies - Ecol. Evol. 4: 4399-4428.

Raymond M., Rousset F. 1995 - Genepop (version 1.2): population genetics software for exact tests and ecumenisms J. Hered. 86(3): 248-249.

Senanan W., Kapuscinski A.R. 2000 - Genetic relationships among populations of northern pike (Esox lucius) - Can. J. Fish. Aquat. Sci. 57: 391-404.

Shafer A.B.A., Wolf J.B.W., Alves P.C., et al. 2015 Genomics and the challenging translation into conservation practice - Trends Ecol. Evol. 30: 78-87.

Van Oosterhout C., Hutchinson W.F., Wills D.P.M., Shipley P. 2004 - MICRO-CHECKER: software for identifying and correcting genotyping errors in microsatellite data Mol. Ecol. Notes 4: 535-538.

Wennerström L., Olsson J., Ryman N., Laikre L. 2017 - Temporally stable, weak genetic structuring in brackish water northern pike (Esox lucius) in the Baltic Sea indicates a contrasting divergence pattern relative to freshwater populations - Can. J. Fish. Aquat. Sci. 74: 562-571.

homzygote and two picks - heterozygote). Orange picks correspond to the GeneScan LIZ 600 size standard. Red arrows in the B25 (Set 1) chromatogram indicate amplified products of this locus (additionally highlighted TAMRA dye exhibits a tendency to raise the ROX dye, while analyzed; therefore it is presented in the picture to avoid misunderstanding).

Supplementary 3. Allele frequencies of the 12 studied msDNA loci in the Esox lucius populations treated as one group and consisting of 668 individuals. 